\title{
Variation in Specificity of Soil-Borne Pathogens from a Plant's Native Range versus Its Nonnative Range
}

\author{
Kurt O. Reinhart, ${ }^{1}$ Wim H. Van der Putten, ${ }^{2,3}$ Tom Tytgat, ${ }^{4}$ and Keith $\mathrm{Clay}^{5}$ \\ ${ }^{1}$ United States Department of Agriculture-Agricultural Research Service, Fort Keogh Livestock \& Range Research Laboratory, \\ 243 Fort Keogh Road, Miles City, MT, 59301-4016, USA \\ ${ }^{2}$ Netherlands Institute of Ecology, Centre for Terrestrial Ecology, Department of Multitrophic Interactions, Boterhoeksestraat 48, \\ 6666 GA Heteren, The Netherlands \\ ${ }^{3}$ Laboratory of Nematology, Wageningen University, Binnenhaven 5, 6709 PD Wageningen, The Netherlands \\ ${ }^{4}$ Department of Ecogenomics, Institute for Water and Wetland Research Radboud, University Nijmegen Huygens, \\ building Heyendaalseweg 135, 6525 AJ Nijmegen, The Netherlands \\ ${ }^{5}$ Department of Biology, Indiana University, Bloomington, IN, 47405-3700, USA
}

Correspondence should be addressed to Kurt O. Reinhart, kurt.reinhart@ars.usda.gov

Received 1 November 2010; Accepted 1 February 2011

Academic Editor: Bradford Hawkins

Copyright (C) 2011 Kurt O. Reinhart et al. This is an open access article distributed under the Creative Commons Attribution License, which permits unrestricted use, distribution, and reproduction in any medium, provided the original work is properly cited.

\begin{abstract}
Existing theory for invasive nonnative species emphasizes the role of escaping specialist enemies. A useful approach is to reciprocally transplant enemies in a controlled and common experiment to quantify the interaction specificity of enemies from plant's native and nonnative ranges. Quantitative measures of interaction specificity, from two experiments with three host genotypes (Belgium, Louisiana, and Pennsylvania) and 37 Pythium isolates (10 Europe and 27 USA), revealed that Pythium pathogens from populations of Prunus serotina in its native range were not host genotype specific while Pythium pathogens from its nonnative range vary with host genotype. This study provides empirical evidence suggesting that Pythium from the nonnative range are either preadapted to or are actively adapting to this host. Although only for a single pathosystem, this study illustrates the importance of understanding enemy impact and host-specificity to assess whether an invader has escaped its natural enemies.
\end{abstract}

\section{Introduction}

Pathogens drive both genetic (e.g., [1]) and species diversity (e.g., [2]) by a shared mechanism-negative frequencydependent disease dynamics which causes more negative effects on the fitness of common species and genotypes than rare forms (reviewed in [1]). Natural enemies also affect biological invasions. The prominent Enemy Release Hypothesis (ERH) has three central underpinnings related to specialization by enemies [3]: "(1) the specialist enemies of the study species (in its native range) will be absent from the new [invaded] region; (2) host switching by specialist enemies of native congeners will be rare; and (3) generalists will have a greater impact on the native competitors." To date, most studies related to ERH have focused on species-level specialization by enemies (e.g., [4]), but the need exists to better understand forms of genotypic specialization (e.g., [57]).

Biological control practitioners have long acknowledged the importance of genotypic forms of specialization and the need for control agents to affect all weed genotypes (e.g., [8]). Furthermore, a positive correlation has been detected between the number of associated pathogens and the outcrossing rate of the host [9]. These examples of genotype specificity help to explain why outcrossing weeds are harder to control with insect biocontrols than selfing plants [10].

Though variation in pathogen impacts is likely an important factor explaining biological invasions [11], little is actually known about the variation in plant-pathogen interactions and their specialization at a biogeographic scale 
(native versus nonnative ranges). One recent study revealed that some enemies are broadly distributed making a complete escape unlikely but avoidance of virulent taxa appeared important [12]. This study was novel because it performed a reciprocal transplant experiment of pathogens (Pythium spp.) from plant's (Prunus serotina) native versus nonnative ranges in a pathogenicity experiment conducted in a controlled environment. The data can be further used to test for genetic effects of the host on disease expression by the different pools of pathogens from the native versus nonnative ranges because the study controlled genetic $\times$ environment interactions which is uncommon relative to other related biogeographic studies. The primary theme of the original paper was on biogeographic variation in pathogen virulence independent of host genotype [12]. Here we reanalyze the data to help identify whether quantitative measures of enemy impact caused by pools of Pythium from either the native or nonnative ranges varied depending on host genotype. Unlike patterns of associational specificity between host and pathogen that do not explicitly characterize enemy impact and do not control for environmental effects, this study describes interaction specificity which refers to how measures of enemy impact vary by host genotype while environmental factors are held constant. Relative to the original study, we test new hypotheses on the interaction specificity of Pythium isolates associated with Prunus in its native and nonnative ranges to determine (1) if host genotype affects disease expression and (2) if the responsiveness to host genotype (i.e., interaction specificity) is greater for Pythium from the host's native than nonnative ranges, an extension of ERH.

\section{Materials and Methods}

Here we reanalyze data from a previous study [12]. They performed two pathogenicity experiments using Pythium isolates, a common soil-borne pathogen, associated with Prunus serotina in its native and nonnative ranges. Both experiments were conducted in the same laboratory under similar controlled conditions, utilized identical growth facilities, and similar experimental designs. Although each experiment used only two host genotypes, the experiments included host genotypes from the nonnative (Belgium) and native ranges (Louisiana and Pennsylvania). Incorporating more genotypes would be ideal but the study provides a minimum number of genotypes to identify whether interaction specificity by pools of Pythium isolates varies in response to host genotype. Since the Pythium isolates are from widely distributed $P$. serotina populations in the native and nonnative ranges, the study does not attempt to specifically compare local pathogens with local host genotypes. The focus of the study is instead on general comparisons of the pools of pathogens when interacting with divergent host genotypes.

2.1. Pathogenicity Experiment 1. Experiment 1 was conducted in two parts testing the effect of Pythium origin on performance of $P$. serotina seedlings. The first part used

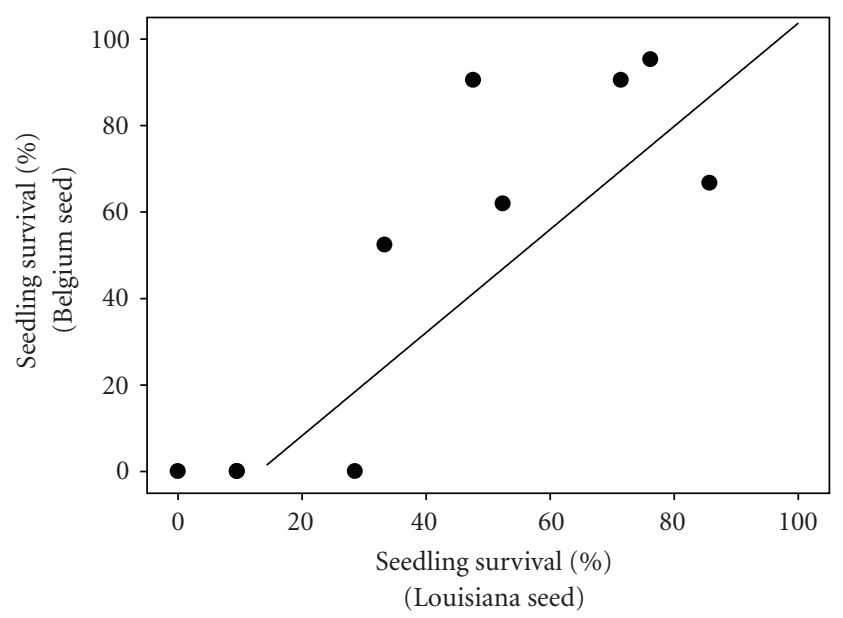

(a)

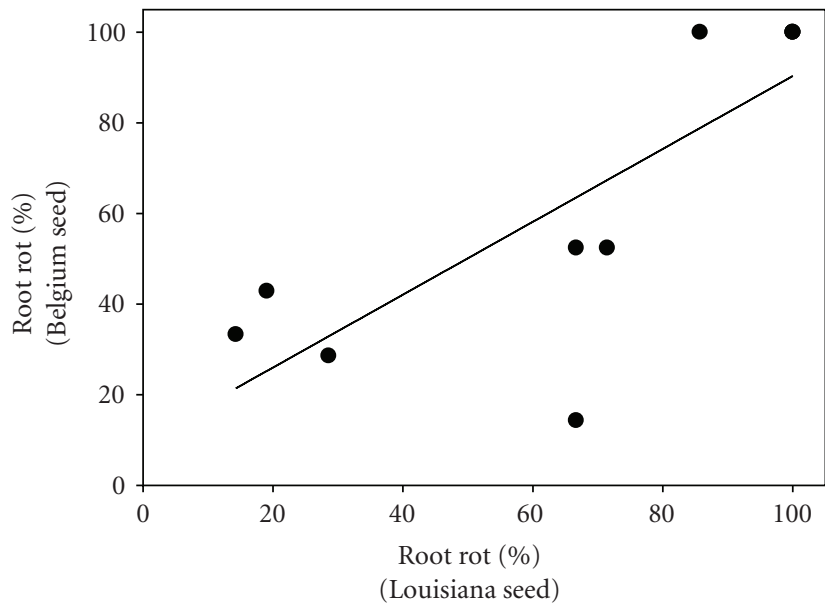

(b)

FIgURe 1: Positive correlation of Prunus serotina seed originating from its native ( $x$-axis, Louisiana, USA) and nonnative ranges $(y$ axis, Belgium) for \% seedling mortality and \% root rot results. A positive correlation suggests that the pathogenic activity of the isolates does not depend on host genotype. Each symbol represents the average response of experimental units ( $n=3$ vessels per isolate) to a given isolate while interacting with seedlings from either the native range ( $x$-axis) or nonnative range ( $y$-axis). Some data points overlap $(n=10)$. All isolates were from the native range and represent a different pool of isolates than shown in Figure 2.

seed originating from the native range (Louisiana, USA) and second part used seed from the nonnative range (Belgium). The two parts differed in their timing and the vessel sizes. The first part used seed from Louisiana, USA, and was started on May 5, 2006, and the second part used seed from Belgium and was started on June 23, 2006. The part using seed from Louisiana was also conducted in smaller experimental vessels (65 versus $100 \mathrm{~mm}$ diameter vessels).

Experiment 1 used Pythium from the native and nonnative ranges $(n=10$ isolates from the native range and $n=$ 3 isolates from the nonnative range) but only data for the larger pool of Pythium from the native range are used here. The pathogenicity experiment used individual isolates to 


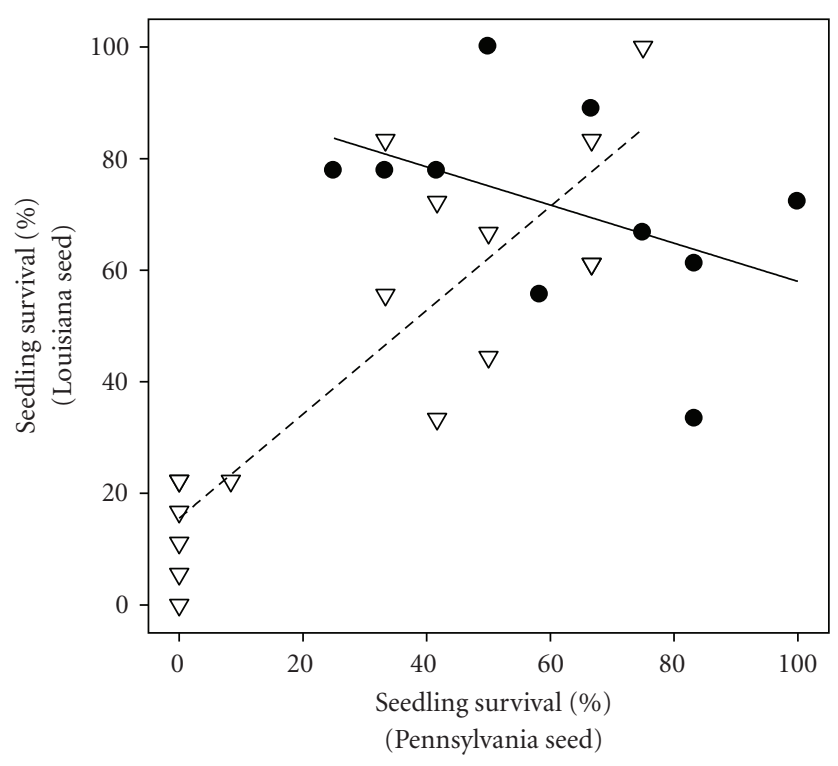

(a)

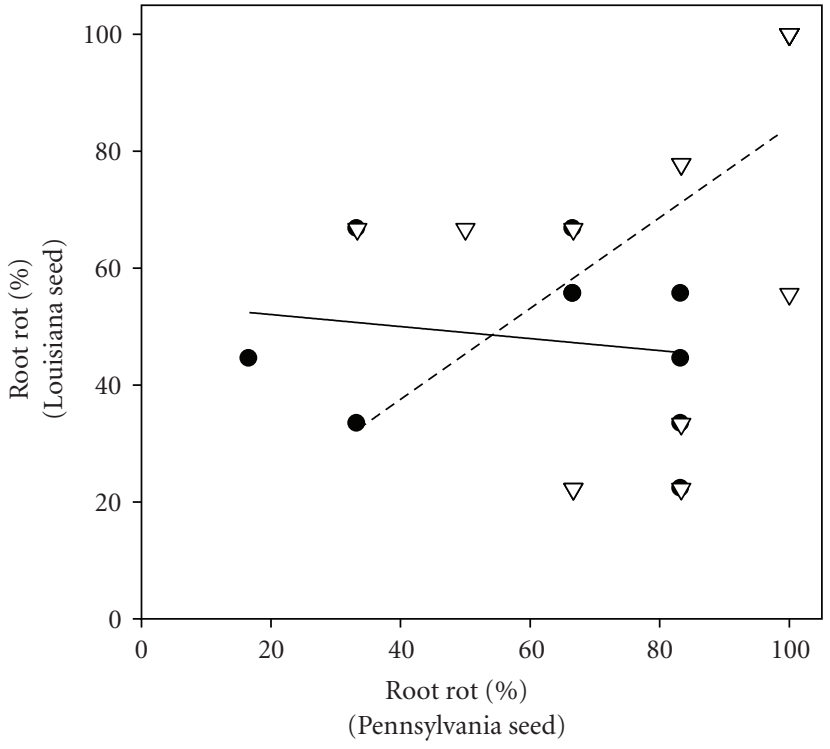

(b)

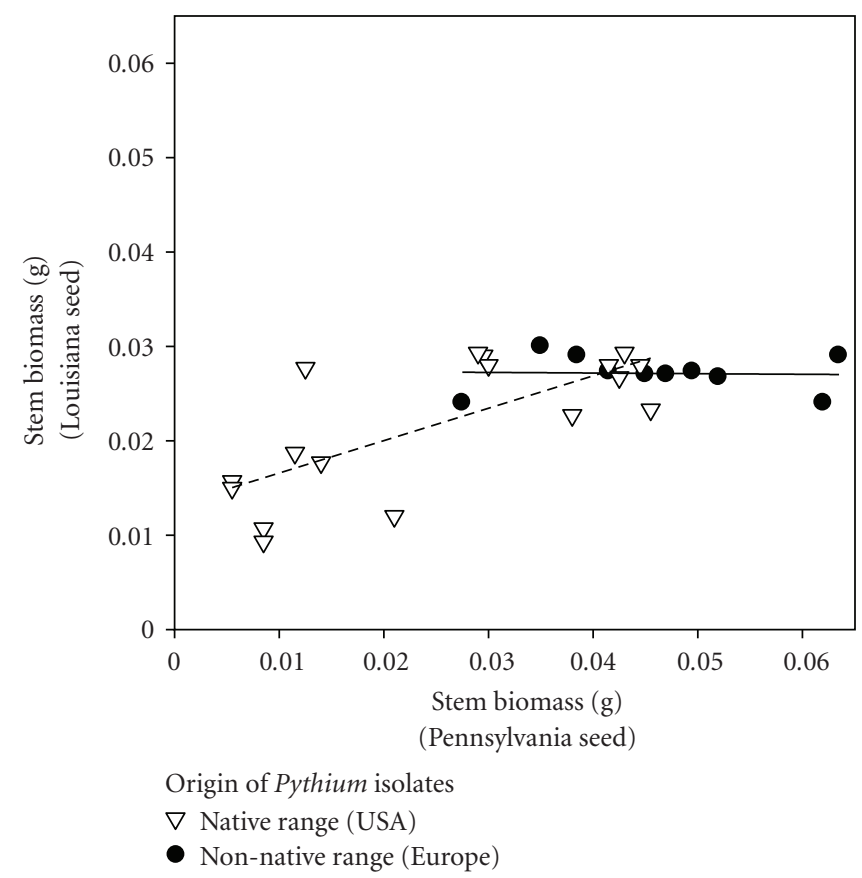

(c)

Figure 2: Effect of isolates of Pythium spp., associated with Prunus serotina trees in their native ( $\nabla: 17$ isolates from USA) and nonnative ranges ( $\bullet: 10$ isolates from western Europe), on the survival, root rot, and stem biomass of $P$. serotina seedlings from two portions of its native range, Louisiana and Pennsylvania, USA. Each symbol represents the average response of experimental units to a given isolate while interacting with seedlings from either Pennsylvania seed ( $n=2$ vessels per isolate) or Louisiana seed ( $n=3$ vessels per isolate). Best fit regression lines are shown and the hatched lines correspond with data for isolates from the native range. Each experimental vessel contained only one isolate and seedlings from only a single seed source. Some data points overlap.

inoculate independent vessels containing seven seedlings of Prunus serotina derived from each seed source. Experimental units were replicated three times per isolate and seed combination. Seedling survival and root rot were quantified for seedlings at ca. 25 days. For our reanalysis, we assume that the two parts of experiment 1 are functionally equivalent and that virulence trends will not be affected by the subtle variations between parts (i.e., start time and vessel size) since other factors were controlled.

2.2. Pathogenicity Experiment 2. Similar to experiment 1, the virulence of 17 Pythium isolates from 13 populations in the 
native range and 10 isolates from six populations in the invaded European range was compared using a controlled pathogenicity experiment conducted in the laboratory [12]. Experiment 2 tested the effect of Pythium isolates from different origins on Prunus serotina derived from seed originating from two regions in the native range (Louisiana $(n=$ 3 replicate vessels per isolate) versus Pennsylvania ( $n=2$ replicate vessels per isolate)). Phylogenetic research has revealed that populations in the nonnative range were likely established from plant material from Pennsylvania, the center of $P$. serotina genetic diversity [13]. Unlike experiment 1, experiment 2 was not broken into parts and was instead performed as one large experiment. In addition, experiment 2 utilized only three seedlings per vessel. Seedling survival, root rot, and stem biomass were quantified for seedlings at 25 days. Further details of the experimental design are provided in the original study [12].

2.3. Analyses. Multiple correlations for different response variables (i.e., seedling survival, root rot, and stem biomass) were made between experimental portions associated with different seed genotypes interacting with a common pool of Pythium isolates. Separate comparisons were made for experiments 1 and 2. Using data from experiment 1, we performed multiple correlations to determine if the pool of isolates interacted similarly (positive correlation) or differently with the two seed sources (Louisiana and Belgium). This was repeated for data from experiment 2 using seed from two sources (Louisiana and Pennsylvania). Positive correlations indicate that the pathogenic activity of the isolates does not depend upon host genotype. Nonpositive correlations suggest that pathogenic activity of the isolates depends on host genotype and that disease symptoms associated with a pool of Pythium are host-genotype specific.

For experiment 2, we assessed whether Pythium from native versus nonnative ranges differed in their specificity for specific host-genotypes by comparing the response variables for seedlings from Pennsylvania and Louisiana with pools of Pythium isolates from either the native or nonnative ranges. This was accomplished by comparing the slopes of the regressions for isolates from the native versus nonnative ranges using multiple ANCOVA analyzes in Proc GLM in SAS version 9.13 (SAS Institute Inc., Cary NC, USA). The response variable for one of the genotypes was included as the covariate. A significant interaction between the treatment and covariate revealed that the slopes differed between isolate pools. Measures of pathogenic activity for the two pools of isolates overlapped but their range limits did not mirror one another. This is not ideal for a comparison of slopes. However, the analyses were still performed since portions of the two data ranges in each comparison overlapped and this variation in ranges is the result of meaningful ecological differences that cannot be controlled.

\section{Results}

3.1. Specificity of Pythium from the Native Range. In Experiment 1 , the pathogenic activity of individual Pythium isolates was similar regardless of whether they interacted with seed from the native versus nonnative ranges (experiment 1; survival, $r=0.86$, and rot root, $r=0.78$, Figure 1$)$. In portion of experiment 2, measures of pathogenic activity were also unresponsive to origin of host material (Louisiana versus Pennsylvania) (survival, $r=0.87$; root rot, $r=0.52$; and stem biomass, $r=0.73$, Figure 2 ).

3.2. Biogeographic Variation in Host Specificity. Contrary to the positive correlations described above, Pythium from the nonnative range (experiment 2) responded differently to different host genotypes (survival, $r=-0.45$; root rot, $r=$ -0.17 ; and stem biomass, $r=-0.04$, Figure 2). Moreover, a significant difference between the slopes of the survival data and biomass data was detected (Figure 2, ANCOVA, $P=.014$ and $P=.015$, resp.) between the Pythium isolates from the native versus nonnative ranges. We observed a similar albeit marginally significant difference between the slopes for the root rot portion of the data $(P=.075)$. Overall, these results indicate biogeographical variation in interaction specialization by pools of Pythium from the native versus nonnative range of $P$. serotina.

\section{Discussion}

The Enemy Release Hypothesis (ERH) has emphasized the importance of escaping host-specific enemies [3] and implicit with this is the assumption that host-specific enemies regulate the abundance of individuals and escaping their effects promotes population growth and invasion. The contribution of pathogens with generalist tendencies, like Pythium [14], is less clear to ERH. Here we show that a pool of Pythium isolates from the nonnative range of an invasive tree $(P$. serotina) is actually more host-genotype specific than two pools from its native range. Specifically, pools of Pythium ( $n=10$ or 17 isolates per experiment) from $P$. serotina's native range responded predictably to varying host genotypes (Louisiana versus Belgium and Louisiana versus Pennsylvania, resp.) suggesting a lack of interaction specificity by the pathogens to different host genotypes. A second experiment compared the interaction specificity of a pool of Pythium from the native $(n=17)$ versus nonnative ranges $(n=10)$ and included host material from two geographically distinct regions in the host's native range (Louisiana and Pennsylvania). Although comparisons with more host genotypes might yield different results, the findings reported here are provocative and suggest a lack of interaction specificity by pools of Pythium isolates from the native range while the pool of Pythium isolates from the nonnative range is considerably more host-genotype specific. The variation in interaction specificity by groups of related pathogens from native versus nonnative ranges reported here seemingly contradicts a major assumption of ERHsuccessful invaders have left their virulent specialist enemies behind [3]. The invading P. serotina appear to have escaped from the most virulent Pythium taxa [12]; however, the pool of Pythium from its nonnative range had pathogenic effects that depended more on host-genotype than those from its 
native range. Thus, Pythium species from the nonnative range ostensibly have greater interaction specificity and are either preadapted to $P$. serotina or adapting to $P$. serotina.

A critical assumption for how pathogens maintain genetic and species diversity is that disease dynamics are host frequency dependent and cycle over time in response to host frequency [15]. We posit that $P$. serotina populations in the native range are in a different stage of the dynamic than conspecifics in invaded European forests. For example, in its native range, $P$. serotina is primarily a subordinate species but in its nonnative range it is locally abundant and can dominate European forests $[12,16]$. If the enemies are poor dispersers (i.e., spatially variable (e.g., [17])) and the hosts are rare (and/or genetically diverse), then the pathogen may be forced to prey on more than one species/genotype to maximize its fitness. In order to utilize more than one host/genotype, the pathogen must be less host-specific than tightly coevolved host-pathogen systems.

In contrast, invaded European forests have higher frequencies of $P$. serotina, based on density and dominance data [12]. Theory based on negative frequency-dependent disease dynamics predicts that enemies will evolve specificity for a prevalent novel host species $[1,18,19]$. Also, invaders often experience founder effects and have less genetic diversity than in their native range [20] increasing the likelihood for specialization to develop. As predicted, invading populations of $P$. serotina have lower genetic diversity and allelic richness relative to populations in their native range corresponding with losses in genetic diversity from a founder effect [13]. Since experiment 2 used host material from Louisiana and Pennsylvania (estimated to be the source material for the host populations in western Europe [13]), variation in pathogenic activity by the pool of Pythium from western European may have been because the comparison included host material that the regional pool was generally familiar versus other sources. This form of interaction specificity may be the trace signature of the development of a more specialized pathosystem between Prunus-Pythium than is typical in its native range. Alternatively, the observed host-specificity may be an artifact of resident Pythium from invaded forests in western Europe being preadapted to P. serotina.

Evidence is accumulating on the importance of generalist pathogens (e.g., [14, 21]) and herbivores [22-24]. Invasive success may depend more on escaping one's generalist enemies than is currently acknowledged by ERH predictions. Exploring the dynamics of host/parasite cycling may help to understand the development of nascent pathosystems and the impending collapse of invasive populations [25]. We should consider utilization of resident enemies to manage the most problematic invasive species (e.g., $[7,26])$. An understanding of resident enemies is of practical significance in evaluating the efficacy of traditional biological controls and determining the potential of resident enemies as biological controls (e.g., [7]). Incorporating resident enemies into an integrated pest management plan for invasive plants is a promising form of biocontrol that could reduce the associated costs, improve success of establishment by utilizing enemies preadapted to the environment, avoid the associated constraints of conducting efficacy trials with restrictive quarantine requirements, and reduce environmental risks of importing "exotic" pests to control the invader. However, invasive species are "moving targets" that are likely to eventually acquire natural enemies that will regulate their populations [27].

\section{Acknowledgments}

The research of K. O. Reinhart was supported by USDANRI (2003-02047) and National Parks Ecological Research Fellowship Program, funded through a grant from the Andrew W. Mellon Foundation helping form a partnership between the National Park Service, the Ecological Society of America, and the National Park Foundation. The authors appreciate Mark West for assistance with statistical analysis and Jennifer Rudgers and Jennifer Koslow for comments on an earlier draft of the manuscript.

\section{References}

[1] K. Clay, K. Reinhart, J. Rudgers, T. Tintjer, J. Koslow, and S. L. Flory, "Red queen communities," in Ecology of Infectious Diseases: Interactions between Diseases and Ecosystems, V. Eviner, F. Keesing, and R. Ostfeld, Eds., pp. 148-178, Princeton University Press, Princeton, NJ, USA, 2008.

[2] J. B. S. Haldane, "Disease and evolution," Current Science, vol. 63, no. 9, pp. 599-604, 1992.

[3] R. M. Keane and M. J. Crawley, "Exotic plant invasions and the enemy release hypothesis," Trends in Ecology and Evolution, vol. 17, no. 4, pp. 164-170, 2002.

[4] L. M. Wolfe, "Why alien invaders succeed: support for the escape-from-enemy hypothesis," American Naturalist, vol. 160 , no. 6, pp. 705-711, 2002.

[5] E. Siemann and W. E. Rogers, "Increased competitive ability of an invasive tree may be limited by an invasive beetle," Ecological Applications, vol. 13, no. 6, pp. 1503-1507, 2003.

[6] D. Garcia-Rossi, N. Rank, and D. R. Strong, "Potential for self-defeating biological control? Variation in herbivore vulnerability among invasive Spartina genotypes," Ecological Applications, vol. 13, no. 6, pp. 1640-1649, 2003.

[7] G. S. Gilbert and I. M. Parker, "Rapid evolution in a plantpathogen interaction and the consequences for introduced host species," Evolutionary Applications, vol. 3, no. 2, pp. 144$156,2010$.

[8] R. Charudattan and A. Dinoor, "Biological control of weeds using plant pathogens: accomplishments and limitations," Crop Protection, vol. 19, no. 8-10, pp. 691-695, 2000.

[9] J. W. Busch, M. Neiman, and J. M. Koslow, "Evidence for maintenance of sex by pathogens in plants," Evolution, vol. 58, no. 11, pp. 2584-2590, 2004.

[10] J. J. Burdon and D. R. Marshall, "Biological control and the reproductive mode of weeds," Journal of Applied Ecology, vol. 18, pp. 649-658, 1981.

[11] C. E. Mitchell and A. O. Power, "Release of invasive plants from fungal and viral pathogens," Nature, vol. 421, no. 6923, pp. 625-627, 2003.

[12] K. O. Reinhart, T. Tytgat, W. H. Van der Putten, and K. Clay, "Virulence of soil-borne pathogens and invasion by Prunus serotina," New Phytologist, vol. 186, no. 2, pp. 484-495, 2010.

[13] B. Petitpierre, Ecological and phylogeographical approach of a biological invasion: Prunus serotina, a case study, M.S. thesis, Université de Lausanne, 2008. 
[14] C. K. Augspurger and H. T. Wilkinson, "Host specificity of pathogenic Pythium species: implications for tree species diversity," Biotropica, vol. 39, no. 6, pp. 702-708, 2007.

[15] P. J. Hudson, A. P. Dobson, and D. Newborn, "Prevention of population cycles by parasite removal," Science, vol. 282, no. 5397, pp. 2256-2258, 1998.

[16] K. O. Reinhart, A. Packer, W. H. Van Der Putten, and K. Clay, "Plant-soil biota interactions and spatial distribution of black cherry in its native and invasive ranges," Ecology Letters, vol. 6, no. 12, pp. 1046-1050, 2003.

[17] K. O. Reinhart and K. Clay, "Spatial variation in soil-borne disease dynamics of a temperate tree, Prunus serotina," Ecology, vol. 90, no. 11, pp. 2984-2993, 2009.

[18] J. B. Gillett, "Pest pressure, an underestimated factor in evolution," Systematics Association Publication Number, vol. 4, pp. 37-46, 1962.

[19] I. M. Parker and G. S. Gilbert, "The evolutionary ecology of novel plant-pathogen interactions," Annual Review of Ecology, Evolution, and Systematics, vol. 35, pp. 675-700, 2004.

[20] B. J. Genton, J. A. Shykoff, and T. Giraud, "High genetic diversity in French invasive populations of common ragweed, Ambrosia artemisiifolia, as a result of multiple sources of introduction," Molecular Ecology, vol. 14, no. 14, pp. 42754285, 2005.

[21] G. S. Gilbert and C. O. Webb, "Phylogenetic signal in plant pathogen-host range," Proceedings of the National Academy of Sciences of the United States of America, vol. 104, no. 12, pp. 4979-4983, 2007.

[22] I. M. Parker and G. S. Gilbert, "When there is no escape: the effects of natural enemies on native, invasive, and noninvasive plants," Ecology, vol. 88, no. 5, pp. 1210-1224, 2007.

[23] J. D. Parker and M. E. Hay, "Biotic resistance to plant invasions? Native herbivores prefer non-native plants," Ecology Letters, vol. 8, no. 9, pp. 959-967, 2005.

[24] J. D. Parker, D. E. Burkepile, and M. E. Hayt, "Opposing effects of native and exotic herbivores on plant invasions," Science, vol. 311, no. 5766, pp. 1459-1461, 2006.

[25] A. J. Kwiatkowska, K. Spalik, E. Michalak, A. Palińska, and D. Panufnik, "Influence of the size and density of Carpinus betulus on the spatial distribution and rate of deletion of forest-floor species in thermophilous oak forest," Plant Ecology, vol. 129, no. 1, pp. 1-10, 1997.

[26] N. M. Kleczewski and S. L. Flory, "Leaf blight disease on the invasive grass microstegium vimineum caused by a Bipolaris sp.," Plant Disease, vol. 94, no. 7, pp. 807-811, 2010.

[27] C. V. Hawkes, "Are invaders moving targets? The generality and persistence of advantages in size, reproduction, and enemy release in invasive plant species with time since introduction," American Naturalist, vol. 170, no. 6, pp. 832843, 2007. 

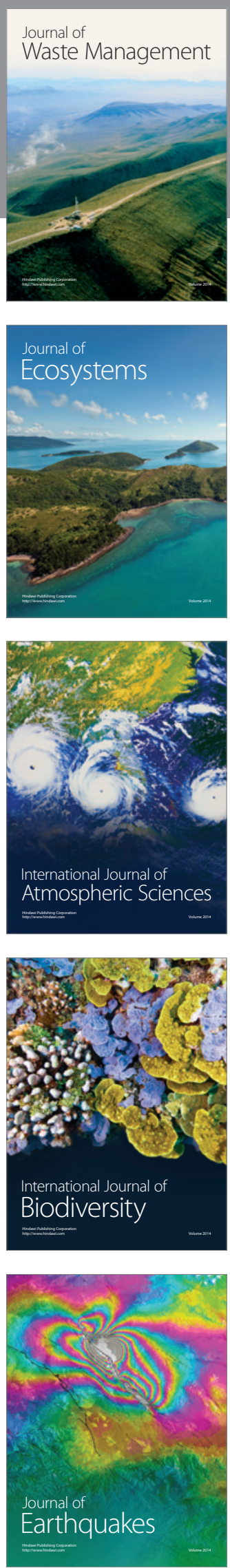
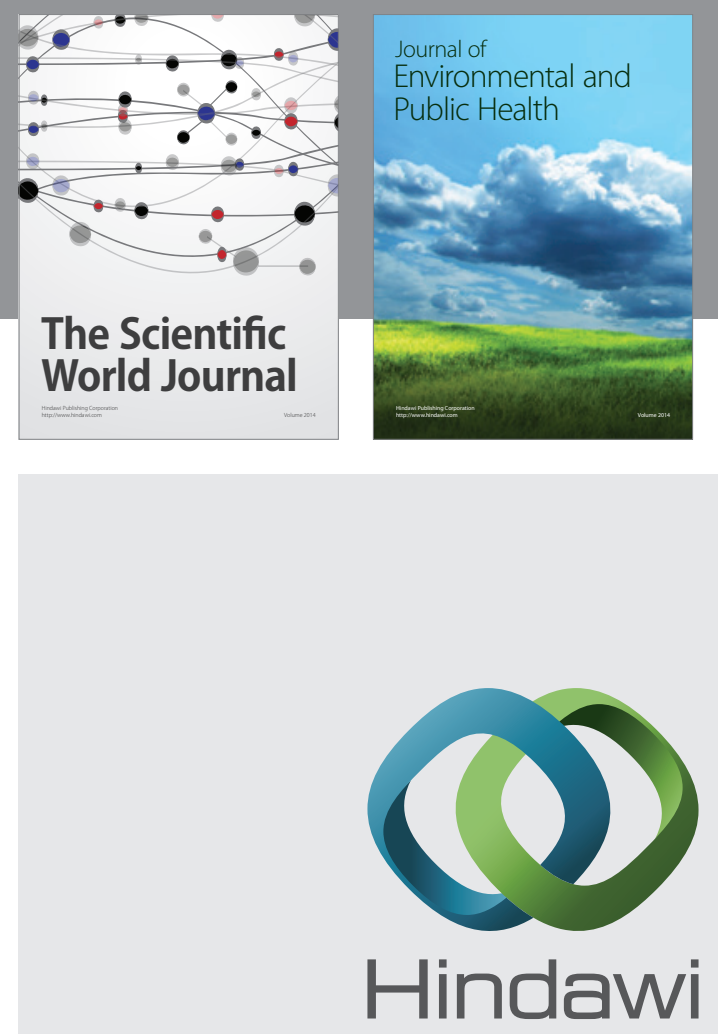

Submit your manuscripts at

http://www.hindawi.com
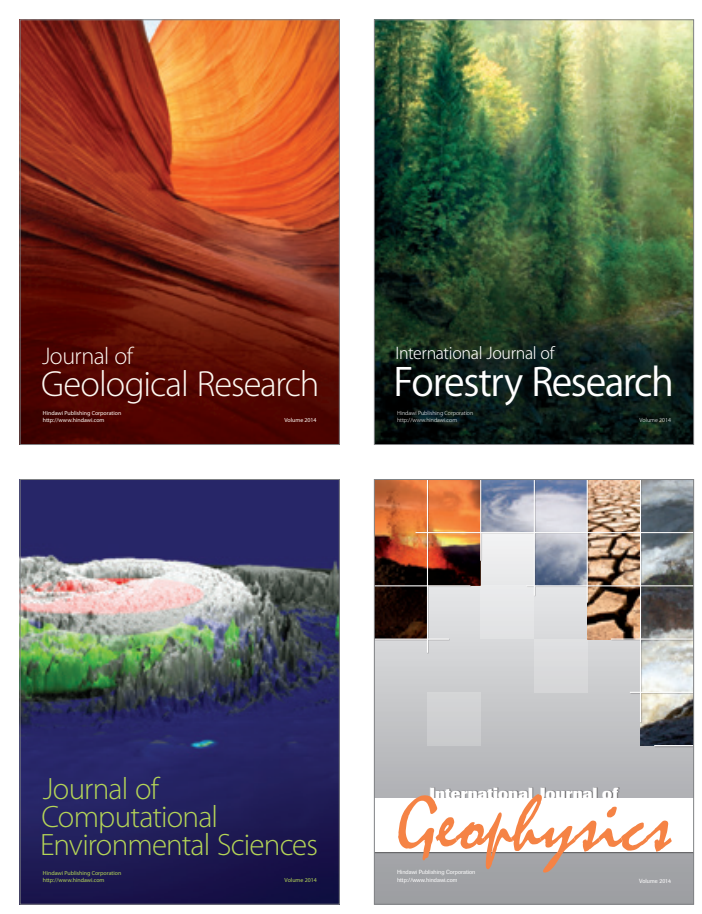
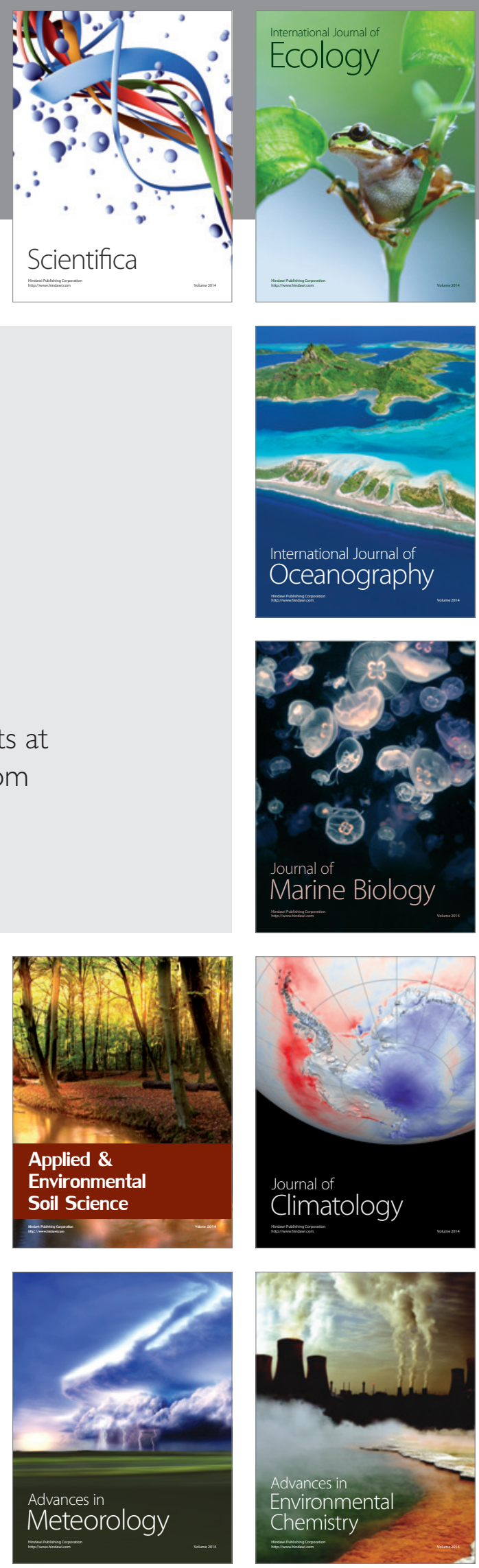